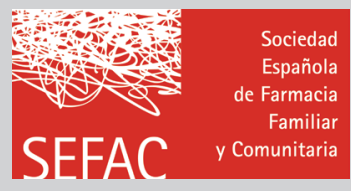

\title{
Adherencia terapéutica: solos no se puede
}

\author{
Jesús C. Gómez \\ Presidente de SEFAC.
}

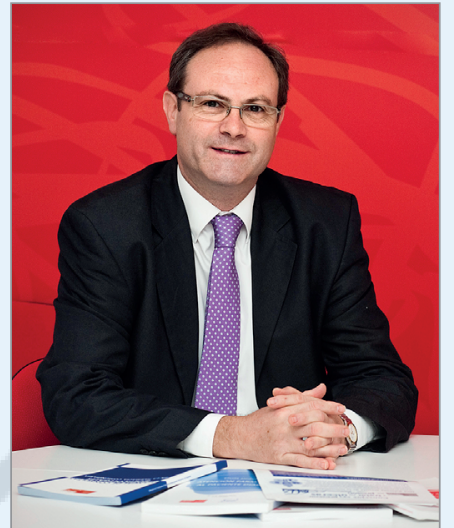

Jesús C. Gómez
¿Por qué muchos pacientes no toman bien sus medicamentos? ¿Estamos explicando bien los efectos de los tratamientos y su forma de seguirlos? ¿Informamos de los posibles efectos secundarios de determinadas terapias? ¿Comentamos suficientemente las consecuencias para la salud de un posible abandono? ¿Compartimos datos entre los distintos agentes de la cadena del medicamento? ¿Lanzamos mensajes homogéneos para no confundir al paciente? ¿Contamos con la opinión de los pacientes para que sean conscientes de por qué tienen que seguir sus tratamientos, cómo, hasta cuándo y qué pueden y no pueden esperar de ellos? Todas éstas y otras muchas son cuestiones que deberíamos plantearnos para encontrar una respuesta a una evidencia cada día más preocupante: la falta de adherencia terapéutica se ha convertido en una realidad tangible y es, hoy por hoy, uno de los principales retos que deben enfrentar los sistemas sanitarios para su buen funcionamiento.

Con una población cada vez más longeva (la población mayor de 65 años en España supone el 17\% y un 5\% tiene más de 80 años), un modelo tendente al aumento de patologías crónicas y un incremento de la polimedicación (hasta el 40\% de los pacientes pluripatológicos presentan tres o más enfermedades crónicas y, de éstos, el 94\% está polimedicado), garantizar que los tratamientos se siguen es fundamental para luchar contra la enfermedad y mantener una buena calidad de vida. Pero para ello hay que dejar definitivamente atrás el enfoque paternalista que subyace en el concepto cumplimiento terapéutico (un paciente pasivo supuestamente tiene que cumplir lo que se le dice sin más, pero no se compromete) y trabajar decididamente para que el concepto adherencia terapéutica (el paciente está comprometido con su tratamiento y sigue un plan trazado junto con los profesionales que le atienden) sea una realidad consolidada. Un paciente inicialmente cumplidor puede abandonar fácilmente su tratamiento cuando no se siente bien o no percibe resultados o puede no seguirlo de forma adecuada sin comunicarlo a los profesionales por falta de confianza. Un paciente adherente será consciente sobre lo que le puede aportar o no su tratamiento, sabrá qué consecuencias puede tener no seguirlo y en caso de detectar algún problema lo comunicará a los profesionales para reevaluar su situación y plantear posibles soluciones.

Sin embargo, queda mucho por hacer. Todos habremos escuchado alguna vez en boca de nuestros pacientes frases como no me sienta bien, son muchas pastillas, no sé para qué me lo estoy tomando, ya no lo necesito... y esto se traduce en unos datos reveladores. En España el 50\% de los pacientes no sigue correctamente la pauta prescrita. Por ejemplo, patologías tan prevalentes como la hipertensión, la diabetes y la EPOC presentan valores bajos de adherencia (sólo son adherentes un 52\%, $56 \%$ y $41 \%$, respectivamente). Otro caso significativo es el de la baja adherencia en los tratamientos para enfermedades infecciosas (solo son adherentes el 54\% de los pacientes), lo que tiene como agravante la generación de resistencias bacterianas y un incremento del riesgo para la salud pública.

Estudios promovidos por SEFAC, como D-VALOR. El valor de la dispensación farmacéutica, también inciden en las dificultades de los pacientes para seguir sus tratamientos, pues más de un 40\% de la población estudiada tiene carencias informativas significativas sobre sus terapias (desconocen su posología, duración, indicación, etc.) y lo mismo indican los resultados preliminares del proyecto Revisa, sobre el servicio de Revisión del Uso de los Medicamentos (RUM), según el cual un $66 \%$ de los pacientes tiene un bajo conocimiento de los medicamentos que conforman su tratamiento.

Todo esto no solo se traduce en un más que posible aumento de la morbimortalidad sino también en un impacto negativo sobre la eficiencia de los recursos empleados para la sostenibilidad de los sistemas de salud. No se puede olvidar que los pacientes con patologías crónicas suponen el $80 \%$ de las consultas en los centros de atención primaria y el 60\% de las estancias hospitalarias, por lo que una baja adherencia tiene una consecuencia directa en 
la eficiencia de los recursos disponibles. Por poner solo un ejemplo, en patologías como la EPOC mejorar en diez puntos la adherencia podría evitar 190.000 exacerbaciones, con un gasto sanitario directo evitable de 80 millones de euros.

\section{Plan de adherencia al tratamiento}

Este marco preocupante es el que ha llevado a organizaciones de distintos colectivos, entre ellas SEFAC, a participar en 2016 en la redacción del documento Plan de Adherencia al Tratamiento. Ésta es una iniciativa promovida por Farmaindustria que recoge algunos de los datos ya mencionados y con la que, por primera vez, se quiere encarar el problema de la falta de adherencia, poniendo negro sobre blanco algunos de sus principales indicadores fundamentales y propuestas para darles una respuesta coordinada en el conjunto del Sistema Nacional de Salud (SNS) para lograr un uso adecuado -que no racionado ni indiscriminado- de los medicamentos. Y lo ha hecho, como se decía en las línea precedentes, reuniendo y recabando la opinión de la gran mayoría de los agentes que tienen responsabilidad en este ámbito: sociedades científicas, corporaciones profesionales, plataformas de pacientes, expertos individuales..

El plan ha suscitado numerosos comentarios y dudas desde su presentación a finales de noviembre en Barcelona. Tampoco ha sido fácil llegar a un consenso durante su redacción; de hecho desde SEFAC creemos que el papel del farmacéutico en general (así lo piensan también las otras sociedades científicas farmacéuticas presentes en el documento como la de hospital y primaria) no está recogido en todas sus posibilidades cuando se trata de hablar de adherencia, y menos aún el del farmacéutico comunitario, que es un agente fundamental para que este tipo de plan sea un éxito. Para SEFAC, que ha estado presente desde el principio tanto en el comité impulsor como en el científico, el documento tiene un valor que va más allá de la situación actual o de intereses legítimos profesionales. Es cierto que el farmacéutico comunitario es un profesional que por sus conocimientos sobre el medicamento, su accesibilidad y sus fuertes vínculos con los pacientes y sus cuidadores, puede y debe desempeñar un rol de gran relevancia en la adherencia terapéutica. No olvidemos que el farmacéutico comunitario es, en muchas ocasiones, tanto la puerta de entrada al sistema como el último profesional sanitario con el que se encuentra el paciente antes de tomar su medicación.

Sin duda, los farmacéuticos comunitarios tenemos una gran responsabilidad y una gran labor por hacer, pues tampoco se puede obviar que con el desarrollo de la receta electrónica los pacientes, en particular los que sufren enfermedades crónicas, visitan con mucha mayor frecuencia las farmacias que las consultas médicas. Por éste y otros motivos, en las farmacias se puede asegurar que el paciente conoce bien su tratamiento, sabe cómo tomarlo según la pauta prescrita, y, en caso contrario, se puede detectar cualquier problema relacionado con la medicación (reacciones adversas, interacciones, duplicidades, abandonos, etc.). Servicios como el RUM, la conciliación de la medicación, los sistemas personalizados de dosificación (SPD) o el seguimiento farmacoterapéutico pueden ser imprescindibles y, ejecutados por los farmacéuticos, deben contribuir de forma decisiva para mejorar la adherencia si se dan también las condiciones y recursos necesarios para ello (posibilidad de acceder a información clínica necesaria, mayor bidireccionalidad en la comunicación con los médicos, etc.).

Esa misma responsabilidad como profesionales es la que como sociedad científica nos lleva a pensar que el abordaje de la adherencia terapéutica no puede llevarse a cabo en solitario y de forma aislada. Es necesaria la implicación y colaboración de médicos, enfermeros, farmacéuticos, pacientes, industria, Administración... Es un problema que afecta a todos y la solución únicamente puede darse si todos los que formamos parte de la cadena de valor del medicamento cumplimos con nuestro cometido, sin recelos, sin enfrentamientos estériles y sin protagonismos mal entendidos que nos alejen del único objetivo que nos debe mover: mejorar la salud de los pacientes.

\section{Comunicarse es compartir}

El plan de Farmaindustria debe entenderse no como un punto y final, sino como un primer paso del difícil camino que debemos encarar para mejorar la adherencia terapéutica. No se ha hecho nada tan ambicioso hasta ahora en este ámbito e implicando a tantos actores, y los agentes que hemos intervenido debemos seguir avanzando en su desarrollo para incorporar todas las mejoras necesarias. En el caso de SEFAC tenemos claro que el farmacéutico comunitario puede aportar mucho más y por eso estamos trabajando ya en un mayor reconocimiento de nuestras competencias en materia de adherencia; no en sustitución de las que otros profesionales de la salud puedan llevar a cabo, pero sí para complementar al máximo de nuestras posibilidades allá donde sea necesario... Porque somos necesarios. Ése será nuestro objetivo, que queremos alcanzar para poder seguir impulsando este proyecto con otras sociedades científicas.

La labor de los farmacéuticos comunitarios es valorada por la población, pero sabemos que aún hay algunas lagunas sobre el potencial real que tiene nuestra profesión. Si esto ocurre con los ciudadanos no debe extrañarnos que también suceda entre algunos profesionales sanitarios como los que ejercen sus especialidades en los hospitales, ya que con los del ámbito de la atención primaria la relación es estrecha. Como decía el filósofo aragonés Baltasar Gracián, cuando los ojos ven lo que nunca vieron, el corazón empieza a sentir lo que nunca sintió. Es decir, al igual que los pacientes que nos visitan a diario en nuestras farmacias, saben valorar nuestra actividad profesional, porque la ven, a medida que esos otros profesionales nos vayan conociendo también nos sabrán apreciar. Comunicarse es compartir y por eso es imprescindible mantener una línea de diálogo permanente entre los profesionales de la salud si queremos transmitir un mismo mensaje inequívoco a los pacientes, para que estos sean activos en el seguimiento de sus terapias y beneficiar así su estado de salud.

Es por todo esto por lo que para SEFAC ha sido de suma importancia mantenerse entre los impulsores de este plan de adherencia, a pesar de las muchas dificultades vividas. Es una forma de que muchos de los sanitarios especialistas allí representados (cardiólogos, psiquiatras, neurólogos, etc.), que no tienen un contacto habitual con los farmacéuticos comunitarios y que, por consiguiente, desconocen nuestras posibilidades, descubran que podemos hacer mucho más que dispensar el medicamento: podemos ayudarles también a que los tratamientos que ellos prescriben logren unos porcentajes de adherencia más elevados en los pacientes ambulatorios. Nadie con sentido común y conocimiento puede considerar que el farmacéutico comunitario debe quedar al margen de los planes para garantizar la adherencia terapéutica.

No obstante, revertir los datos de la preocupante falta de adherencia terapéutica con los que hoy convivimos no es tarea fácil y será directamente imposible si pensamos (no ya los farmacéuticos, sino el conjunto de agentes del sector) que podemos hacerlo solos, yendo cada uno por nuestro lado. Porque solos no se puede y los pacientes confían en nosotros para resolver sus necesidades terapéuticas. 